\title{
COMPETITION, MORTALITY, AND DEVELOPMENT OF SPATIAL PATTERNS IN TWO CANTABRIAN POPULATIONS OF FAGUS SYLVATICA L. (FAGACEAE)
}

\author{
by \\ VICENTE ROZAS ${ }^{1}$ \& JOSÉ ANTONIO FERNÁNDEZ PRIETO ${ }^{2}$ \\ 1 Unidad de Botánica, Departamento de Biología de Organismos y Sistemas, \\ Universidad de Oviedo. Catedrático Rodrigo Uría. E-33071 Oviedo (Asturias). \\ e-mail: vrozas@sci.cpd.uniovi.es \\ 2 Instituto de Recursos Naturales y Ordenación del Territorio. Independencia, 13. \\ E-33004 Oviedo (Asturias).
}

\begin{abstract}
Resumen
Rozas, V. \& J.A. Fernández Prieto (2000). Competencia, mortalidad y desarrollo de los patrones espaciales en dos poblaciones cantábricas de Fagus sylvatica L. (Fagaceae). Anales Jard. Bot. Madrid 58(1): 117-131 (en inglés).

En el presente trabajo se analizan las distribuciones espaciales de tamaño y mortalidad en poblaciones de haya (Fagus sylvatica $\mathrm{L}$.) incluidas en dos parcelas de bosque atlántico. En general, el crecimiento radial de $\boldsymbol{F}$. sylvatica es directamente proporcional al tamaño e inversamente proporcional a la competencia intraespecífica, mientras que la mortalidad parece estar condicionada por competencia con individuos de la misma especie. La población formada sobre todo por árboles coetáneos presenta características espaciales indicativas de una intensa competencia intraespecífica entre árboles vecinos, como lo son la ausencia de una distribución ordenada de tamaños, regularidad local de los árboles vivos y un patrón regular en los árboles dominantes. La población incluida en bosque maduro presenta una disposición ordenada de los tamaños, resultante de una extensa repulsión entre árboles pertenecientes a distintas cohortes. En esta población, la mayoría de la mortalidad tiene lugar dentro del denso grupo de individuos pequeños, produciendo regularidad en las hayas supervivientes. El patrón aleatorio de las hayas dominantes puede ser explicado por la actuación de factores exógenos o de procesos de autoatenuación.
\end{abstract}

Palabras clave: Fagaceae, Fagus sylvatica L., dinámica forestal, patrón espacial, autocorrelación espacial, estructura de edad, competencia, mortalidad.

\begin{abstract}
RozAs, V. \& J.A. FernándeZ Prieto (2000). Competition, mortality, and development of spatial patterns in two Cantabrian populations of Fagus sylvatica L. (Fagaceae). Anales Jard. Bot. Madrid 58(1): 117-131.

In this paper the spatial patterns of size and mortality of European beech (Fagus sylvatica L.) were analysed in two deciduous forest plots of Northern Spain. In general terms, radial growth of $F$. sylvatica yields a direct relationship with size and an inverse relation with intraspecific competition while tree mortality seems be related to intraspecific competition. In the overall even-aged population, a lack of a recognisable structure in tree-size distribution, a small-scale regularity of survivors, and a regular pattern of dominant trees was noticed. This is a consequence of intense intraspecific competition at local level. In the old-growth plot, the wide repulsion between small and large beeches yields a specific spatial structure in tree-size distribution, showing even-sized groups of trees in different stages. Mortality in this plot occurs mainly within the dense group of small trees, which produces a broad regular pattern among the live beech trees. The random spatial pattem of dominant beeches seems to be characteristic of old-growth forests and could be a consequence of either self-thinning processes or exogenous factors.
\end{abstract}

Key words: Fagaceae, Fagus sylvatica L., forest dynamics, spatial pattern, spatial autocorrelation, age structure, competition, mortality. 


\section{INTRODUCTION}

A common tenet in forest ecology is the assumption that trees of smaller sizes follow a clumped distribution while larger sized ones are randomly or uniformly distributed (SZWAGRZYK, 1992; WARD \& al., 1996). The aggregation of small individuals can be well explained by a variety of causes such as the existence of vegetative reproduction, the occurrence of disturbances that release space suitable for new establishment, forestfloor heterogeneity, competition, and others (LePs \& KindlmanN, 1987). The development of spatial patterns, from aggregation to regularity, is usually interpreted as a consequence of densitydependent processes, so that mortality would take place in the high density zones and consequently a more sparse distribution of surviving trees would be given (KENKEL, 1988). However, evidence of a uniform spatial pattern for the large dominant individuals has been scarcely documented in natural populations of forest trees (MOEUR, 1993), while examples of a random pattern are quite abundant (SZWAGRZYK, 1992).

The main ecological factor identified as the most important cause of mortality and, thus, of spatial pattern transformation, is the competition between neighbouring trees (LePS \& KindLManN, 1987; KenKel, 1988). The interaction between neighbour individuals promotes the diversification of tree growth-rates within the same initial size class (WEINER, 1984), giving way to a new size differentiation among individuals so that the dominant and suppressed categories arise. Such divergence, in addition, tends to increase in the course of time, as the interaction between both given categories is not symmetric (WEINER, 1990). The loss of vigour experienced by underlying trees increases their susceptibility to direct mortality agents (LONG \& SMITH, 1984) increasing the probability of those individuals dying. In monospecific stands constituted by even-aged trees, mortality occurrence is a consequence of intraspecific competition, and leads to a more regular spatial pattern of surviving trees than would be expected when assuming that mortality is a random event (KENKEL, 1988).

In natural forests, substantial differences between the growth rates of trees of the same species are very frequent, particularly in cohorts of shade-tolerant species, which can survive for a long time as underlying individuals (PETERKEN, 1996). As a result of this, the size hierarchy that is present in this type of forests is a consequence of both the unequal age of trees and the diversification in growth-rates of trees belonging to the same cohort. Another factor which also explains to a certain extent the different spatial patterns of trees, is the regeneration mode of the species, being typical in shade-tolerant species the establishment in a continuous way under the forest canopy (VEBLEN, 1992). Therefore, the relative spatial arrangement of the different size classes can be related to a specific regeneration mode (VEBLEN \& al., 1980; MOEUR, 1993). This assertion suggests that quantitative spatial analysis would provide a better knowledge of forest dynamics as a whole than those designs based on the subjective identification of canopy gaps, often considered as independent units (LIEBERMAN \& $a l ., 1989$ ).

The aim of this paper is to test the following hypotheses related to the spatial dispersion and the growth and mortality patterns of the shade-tolerant hardwood species Fagus sylvatica L. in a deciduous forest of Northern Spain: (1) the individuals belonging to any given size class are randomly distributed, (2) the sizes of neighbouring trees are independent, (3) the increase in basal area is independent of competition intensity and (4) the mortality is not related to competition and it does not give a shift in spatial pattern of the survivors. The decay of dead trees from the studied plots is a main limitation for the proper accomplishment of these objectives. Thus, only those dead trees that could be accurately identified, which represent the most recent mortality, were taken into account. In spite of this restriction, the results obtained allow valid conclusions on the dynamics of the 
studied populations of Fagus sylvatica, and on the development of its spatial patterns to be drawn.

\section{MATERIAL AND METHODS}

\section{Study area}

The study area is located in the western lowlands of Cantabria, Northern Spain $\left(43^{\circ} 20^{\prime} \mathrm{N}, 4^{\circ} 18^{\prime} \mathrm{W}\right)$, and included in the Corona forest and the Oyambre Natural Park, between the towns of Comillas and Cabezón de la Sal. The forest under study has a surface of 110 ha and both European beech (Fagus sylvatica L.) and pedunculate oak (Quercus robur L.) dominate its canopy. Other relevant woody species present are Ilex aquifolium L., Salix atrocinerea Brot., Pyrus cordata Desv., Frangula alnus Mill., Corylus avellana L., Crataegus monogyna Jacq. and Malus sylvestris Mill. The soil of the location is classified as sandy brown earth (GUITIÁN \& al., 1985) with parent material of sandstone and clay formed in the lower Cretacean (IGME, 1976). It is located on a hillside North-Northeast oriented, with slopes that range from 8 to $50 \%$, and altitudes from 40 to $240 \mathrm{~m}$. The climate is Atlantic with the summer as the warmest and driest season (ALLUE, 1990), a total annual precipitation of $1400 \mathrm{~mm}$, and $13.5^{\circ} \mathrm{C}$ as the average annual temperature.

\section{Sampling}

Two rectangular plots, $\mathrm{C} 2$ and $\mathrm{C} 3$, with a surface of $0.25 \mathrm{ha}(50 \times 50 \mathrm{~m})$ and $0.30 \mathrm{ha}(50$ $\times 60 \mathrm{~m}$ ), respectively, were located in the forest interior. Stands were selected on the basis of: (1) the existence of populations of Fagus sylvatica composed of an adequate number of trees belonging to a wide size range, (2) the presence of enough dead individuals within these populations and (3) the existence of a regular topography with a low slope that facilitated the field work and guaranteed a minimal error in the measurements. The plots were divided into quadrats of $10 \times 10 \mathrm{~m}$ and all living and dead trees with DBH (stem diameter at $1.3 \mathrm{~m}$ above ground) $\geq 2 \mathrm{~cm}$ were identified, labelled, and their DBH measured. Dead trees category included the standing, windthrown and snapped dead trees, as well as the stumps, which were identified by their bark and wood characteristics. The $x$ and $y$ co-ordinates to the centre of each tagged stem were measured within each quadrat to the nearest $0.1 \mathrm{~m}$. Only the largest stem of the few multi-stemmed trees was measured, and each apparently independent stem was considered as a separate individual.

\section{Tree age estimates}

All the live Fagus sylvatica trees with DBH $\geq 5 \mathrm{~cm}$ were cored with a Pressler increment borer. Trees with DBH $<30 \mathrm{~cm}$ were cored at $20 \mathrm{~cm}$ above ground, while in trees with $\mathrm{DBH} \geq 30 \mathrm{~cm}$ cores were taken at $100 \mathrm{~cm}$ above ground. Cores were air-dried, mounted, and sanded using successively finer grades of sandpaper until the growth rings were clearly visible. In cores that reached the pith of the tree, its age was estimated either as the number of existing rings in the sample obtained by ring counts, if the core included less than 100 rings, or by crossdating with a master chronology, if the core included more than 100 rings. Crossdating permitted recognition of some absent rings in the samples that could not have been identified by other methods. If the core did not reach the pith, its position was estimated by means of the extension of two xylematic rays visible on the sample surface. The number of absent rings in the missed segment of the core was estimated by means of an initial growth model calibrated from samples of Fagus sylvatica that reached the pith (RozAS, 1999). The estimated number of absent rings and the number of rings in the available segment have been summed in order to obtain the overall estimates of tree age. It has been proved that this method of age estimate gives a mean absolute deviation of 8.8 years for incomplete cores of $F$. sylvatica distant up to $5 \mathrm{~cm}$ from the pith (ROZAS, 1999). Mean age difference between 20 and $100 \mathrm{~cm}$ above ground is 
11 years, which have been obtained from 20 trees cored at both heights. Thus, 11 years were added to age estimates of trees cored at $100 \mathrm{~cm}$ above ground in order to obtain all age estimates referred to a height of $20 \mathrm{~cm}$ above ground level.

\section{Spatial analysis}

Univariate spatial pattern was analysed using the Ripley's $K$ function (UPTON \& FINGLETON, 1985; HAASE, 1995), which reflects the type, scale and intensity of the spatial pattern of a set of points from the distances between all of them. $K(t)$ function computes the number of neighbouring trees $j$ that are found within a distance $t$ from each focal tree $i$. Edge effect was corrected by the weighted method, which assigns a higher weight to peripheral trees in the plot than to central ones. The weight assigned to each tree is inverse to the proportion of circumference centred on point $i$, that passes through the point $j$, lying within the plot boundaries (MOEUR, 1993; HaAse, 1995).

Bivariate spatial pattern was analysed using the bivariate extension of Ripley's $K$ function (UPTON \& FINGLETON, 1985), which indicates the type, scale and intensity of the spatial interaction between two sets of points. The function $K_{12}(t)$ computes the number of type 2 trees within circles of radius $t$ centred at each type 1 tree. Edge effect was corrected by means of the same method as in the univariate analysis. $K(t)$ as well as $K_{12}(t)$ values were calculated each $1 \mathrm{~m}$, for a maximum distance of $25 \mathrm{~m}$, and only sets of points with more than 10 individuals were analysed.

The spatial randomness hypothesis for univariate analysis was tested by means of Monte Carlo methods, simulating random coordinates of the same number of trees as in the analysed sample. A $95 \%$ confidence interval for spatial randomness was obtained from high and low $K(t)$ values for each distance $t$ calculated in 20 simulations. The spatial independence hypothesis for bivariate analysis was verified by simulating random toroidal shifts of the type 2 trees with respect to the type 1 ones (UPTON \& Fingleton, 1985). A $95 \%$ confidence interval for spatial independence was generated from high and low $K_{12}(t)$ values for each distance $t$ obtained in 20 simulations. Since often $K_{12}(t) \nsim K_{21}(t)$, the spatial interaction between two sets of trees was calculated as a linear combination of both bivariate analyses (UPTON \& Fingleton, 1985). The random mortality hypothesis was tested by selecting at random and removing trees from the pre-mortality population composed of the set of live + dead trees (Kenkel, 1988; DunCan, 1991). The number of individuals removed in each simulation corresponded to the number of dead trees in the sample. A $95 \%$ confidence interval for random mortality was given from high and low $K(t)$ and $K_{12}(t)$ values for each distance $t$ attained in 20 simulations.

All obtained results were converted into the functions $L(t)=[K(t) / \pi]^{1 / 2}$ for univariate analysis and $L_{12}(t)=\left[K_{12}(t) / \pi\right]^{1 / 2}$ for bivariate analysis, in order to linearise the function and stabilise the variance. The interpretation of results was made by plotting $L(t)-t$ or $L_{12}(t)-t$ against $t$, which fit null hypothesis to zero value. For univariate analysis, values of $L(t)-t$ above upper boundary of confidence intervals indicate a clumped pattern, whilst values below lower boundary indicate a uniform pattern. The extent to which the observed distribution departs from the randomness was calculated by applying the transformation $W(t)$ (SZWAGRZYK, 1992). For bivariate analysis, values of $L_{12}(t)-t$ above upper boundary of confidence intervals indicate attraction, whilst values below lower boundary indicate repulsion.

The spatial structure of the DBH variable within each set of trees was analysed by the standard normal deviates $z(d)$ of Moran's $I$ spatial autocorrelation coefficient (UPTON \& Fingleton, 1985). Computation was made at $2.5 \mathrm{~m}$ distance classes and only intervals with at least 20 pairs of neighbouring trees were included in the analysis (DUNCAN \& STEWART, 1991). The null hypothesis of independence in size among neighbouring trees was tested by means of the confidence interval defined by the 0.05 significance level 
values for a standard normal distribution. Values of $z(d)$ greater than 1.96 indicate positive autocorrelation, while values less than -1.96 indicate negative autocorrelation. An overall test for each correlogram was performed by checking whether at least one value was significant at the $0.05 / k$ level, where $k$ is the number of distance classes analysed, according to the Bonferroni's criterion for multiple tests (LEGENDRE \& ForTin, 1989; DUNCAN \& STEWART, 1991).

If a correlogram shows positive autocorrelation at small distance classes, then trees of similar size are grouped together. In order to identify even-sized groups of trees, a measure of association reflecting both spatial proximity and size similarity was calculated between each pair of trees (DUNCAN \& STEWART, 1991). Agglomerative hierarchical clustering and nonmetric multidimensional scaling were applied to the symmetrical matrices of association measures in order to group trees of similar size and spatial location. The groups of trees recognised from the cluster and the ordination diagram should be spatially discrete, even-sized and with a different size than adjacent ones (DUNCAN \& STEWART, 1991; DUNCAN, 1993).

\section{Radial growth and competition}

In each of the core samples, widths of the outermost 5 rings were measured to the nearest $0.01 \mathrm{~mm}$ under dissecting microscope, with an incremental measuring device (Velmex measuring stage, Acu-Rite linear encoder, and Metronics digital readout unit linked to a PC). The basal area increment of each tree in the last 5 years (BAI5) was calculated from $\mathrm{DBH}$ and the ring widths of the last 5 years, period in which the environmental conditions of the forest have not drastically changed. It was calculated a competition index defined as (modified from LORIMER, 1983):

$$
C I=\sum_{\mathrm{j}=1}^{n} \frac{B A \mathrm{j}}{B A_{\mathrm{i}}}
$$

where $C I$ is the competition index, $B A_{\mathrm{i}}$ is the basal area of the focal tree $i$, and $B A_{\mathrm{j}}$ is the basal area of neighbouring trees $j$. This index was calculated for the focal Fagus sylvatica trees distant at least $5 \mathrm{~m}$ from the plot boundaries, being considered as neighbours all trees located at a distance $05 \mathrm{~m}$ from the focal tree. Intraspecific competition index was calculated by considering only the neighbours $F$. sylvatica, while interspecific competition index was calculated from neighbouring trees belonging to all species except $F$. sylvatica.

\section{RESULTS}

The shape of the DBH distribution of Fagus sylvatica in the plot $\mathrm{C} 2$ is descending monotone, with dead trees included in the first two size classes, always narrower than $20 \mathrm{~cm}$ in DBH (fig. 1a). While mature trees older than 200 years are very scarce, the population of $F$. sylvatica in plot $\mathrm{C} 2$ largely consists of trees with ages ranging from 40 to 80 years old (fig. 1b). In plot $\mathrm{C} 3$ the $\mathrm{DBH}$ distribution is compound, consisting of a steeply descending monotone in the two smallest size classes and a broad peak in the size classes larger than $20 \mathrm{~cm}$ (fig. 1c). Dead trees are found in both the first size-class, ranging from 2 to $10 \mathrm{~cm}$ in DBH, and the first two sizeclasses of the wide peak, from 20 to $40 \mathrm{~cm}$ in DBH. The age structure of $F$. sylvatica in plot C3 reveals two well differentiated cohorts, one composed largely of mature trees 200 to

\section{TABLE 1}

DBH CLASSES CONSIDERED FOR THE SPATIAL ANAL YSES AND NUMBER OF FAGUS SYLVATICA TREES IN EACH SIZE CLASS

\begin{tabular}{|c|c|c|c|c|c|}
\hline Size class & $\begin{array}{c}\text { DBH range } \\
\text { (cm) }\end{array}$ & \multicolumn{2}{|c|}{ Plot C2 } & \multicolumn{2}{|c|}{ Plot C3 } \\
\hline & & Live & Dead & Live & Dead \\
\hline 1 & 2- 4.9 & 31 & 9 & 118 & 28 \\
\hline 2 & 5- 9.9 & 39 & 9 & 61 & 0 \\
\hline 3 & $10-29.9$ & 62 & 1 & 56 & 4 \\
\hline 4 & $30-80$ & 18 & 0 & 35 & 1 \\
\hline \multicolumn{2}{|c|}{ TOTAL } & 150 & 19 & 270 & 33 \\
\hline
\end{tabular}

Number of live and dead trees, with DBH $2 \mathrm{~cm}$, by plots and within each size class. 


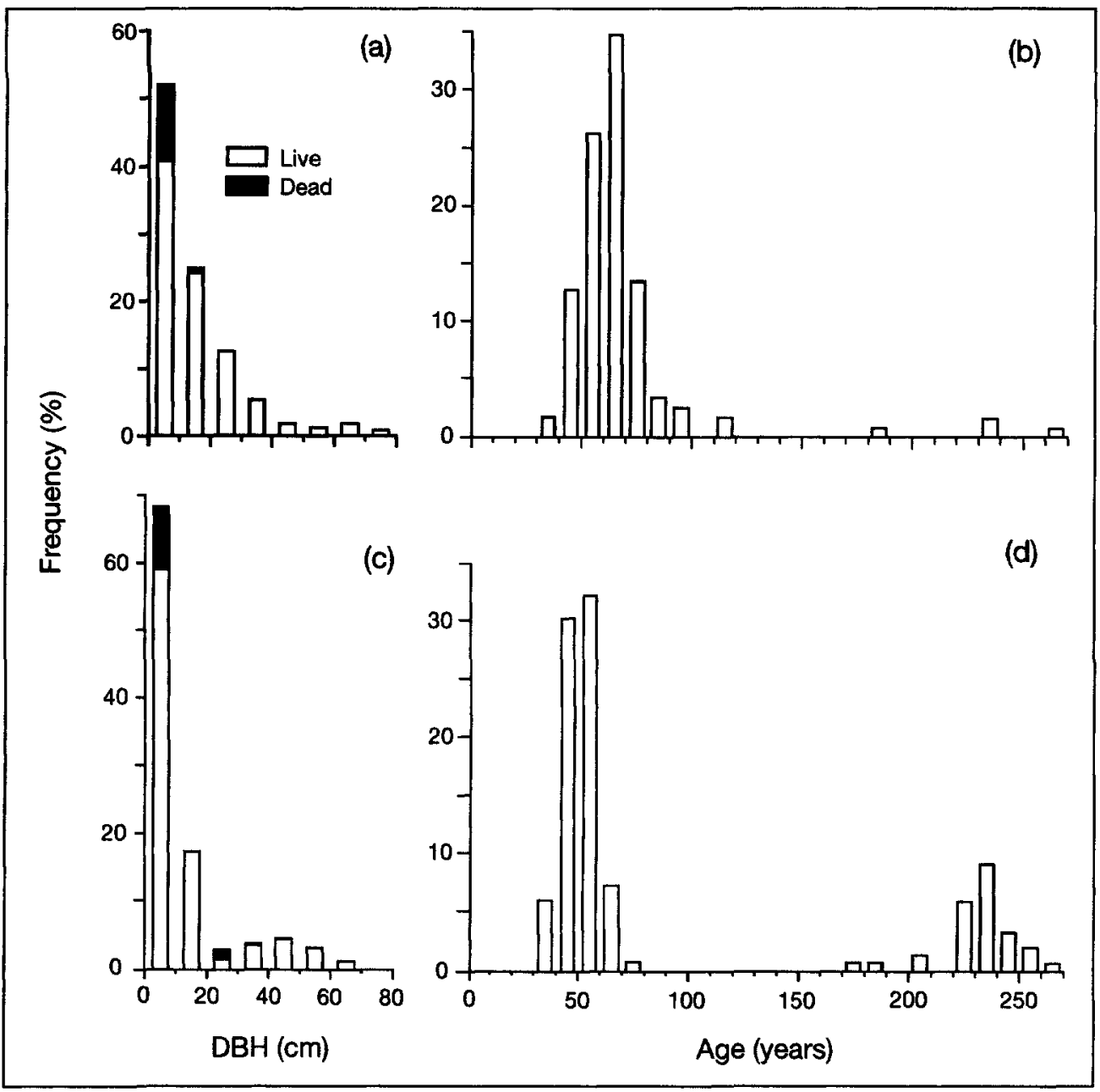

Fig. 1.-DBH distributions in $10 \mathrm{~cm}$ classes for Fagus sylvatica in plots $\mathrm{C} 2$ (a) and $\mathrm{C} 3$ (c). Age distributions in 10-yearold classes for $F$. sylvatica in plots $\mathrm{C} 2$ (b) and $\mathrm{C} 3$ (d). Size structures include all live and dead individuals with DBH $\geqslant$ $2 \mathrm{~cm}$, while age structures include all live individuals with $\mathrm{DBH} \geqslant 5 \mathrm{~cm}$.

260 years old and another being a more recent cohort composed of 30 to 70 years old trees (fig. 1d).

Both populations of Fagus sylvatica were classified into four size-classes for stratified spatial analysis (table 1). The total number of dead trees in plot $\mathrm{C} 2$ was 19 , whereas in plot $\mathrm{C} 3$ it was equal to 33 , with a total proportion of dead trees around $11 \%$ in both plots. In plot $\mathrm{C} 2$, the size-classes 1 and 2 of $F$. sylvatica were mainly clumped, the sizeclass 3 showed aggregation and random pattern according to spatial scale, while the size-class 4 exhibited a uniform and random pattern, according to the analysed spatial scale (fig. 2a). In plot C3, the size-classes 1 to 3 showed different intensity of clumping, while trees belonging to the size-class 4 were distributed at random in all the spatial scales analysed (fig. 2b).

The correlogram for spatial structure of DBH in the Fagus sylvatica population of plot C2 does not show any significant autocorrelation in all the analysed distances and has not overall significance (fig. 3a). In the $F$. sylvatica population of plot $\mathrm{C} 3$ (fig. $3 \mathrm{~b}$ ) 


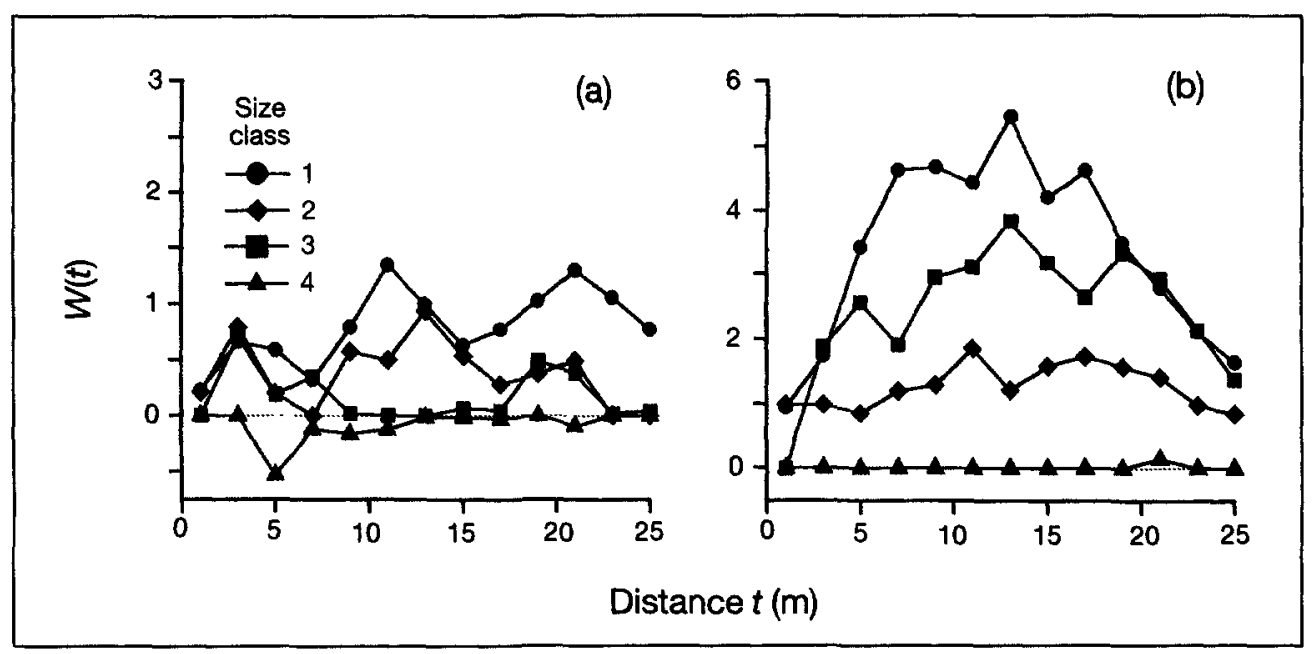

Fig. 2.-Spatial pattern analysis of Fagus sylvatica, stratified by size classes. $W(t)$ : deviation of the empirical function $L(t)-t$ from the $95 \%$ confidence interval for random distribution hypothesis, in plots $\mathrm{C} 2$ (a) and C3 (b). against distance $t$. Positive values: clumped spatial pattern. Zero: random pattern. Negative values: uniform pattern.

the correlogram for spatial structure of DBH is highly significant as a whole and the first four distance-classes, from 0 to $10 \mathrm{~m}$, showed significant positive autocorrelation indicating similarity in neighbouring tree diameters at this spatial scale. The correlogram for plot C3 exhibits furthermore significant positive autocorrelation at distance class $8(20 \mathrm{~m})$ and negative autocorrelation at distance classes 17 to 23 ( 42.5 to $57.5 \mathrm{~m}$ ). Four even-sized groups of $F$. sylvatica were given in plot $\mathrm{C} 3$ (table 2). Group 1 included large trees with an average of $48.6 \mathrm{~cm}$ in DBH and without dead trees, which dominated half of plot $\mathrm{C} 3$ (fig. 3c; table 2). Group 2, by contrast, included numerous small trees, with a mean size of $5.7 \mathrm{~cm}$ in DBH. A proportion of $88 \%$ of total dead $F$. sylvatica trees in plot C3 were included in group 2, which dominates the opposite half of the plot (fig. 3d; table 2). The other two groups of trees with intermediate diameters were intermixed with the principal groups 1 and 2. Dead $F$. sylvatica trees included in group 3 (table 2) were underlying individuals developed under dominant trees belonging to group 1 .

In both $\mathrm{C} 2$ and $\mathrm{C} 3$ plots, age and size of Fagus sylvatica were significantly related (least-squares regression in plot $\mathrm{C} 2$ : $\log _{\mathrm{e}}$ (age) $=0.33 \log _{\mathrm{e}}(\mathrm{DBH})+3.25 ; r^{2}=0.48 ; n=118$; $p<0.001$ and in plot $\mathrm{C} 3: \log _{\mathrm{e}}(\mathrm{age})=0.78$ $\log _{e}(\mathrm{DBH})+2.22 ; r^{2}=0.79 ; n=152 ; p<$ $0.001)$. Therefore, spatial interaction between different size-classes can be used to estimate

TABLE 2

GROUPS OF FAGUS SYLVATICA TREES IDENTIFIED IN PLOT C3

\begin{tabular}{|c|c|c|c|c|}
\hline Group of trees & $n$ & No. of dead trees & $\begin{array}{c}\text { Mean DBH } \pm 1 \\
\text { standard error }(\mathrm{cm})\end{array}$ & $\begin{array}{c}\text { DBH range } \\
(\mathrm{cm})\end{array}$ \\
\hline 1 & 25 & 0 & $48.6 \pm 1.6$ & $31.4-64.7$ \\
2 & 243 & 29 & $5.7 \pm 0.2$ & $2.0-17.6$ \\
3 & 12 & 4 & $33.5 \pm 1.5$ & $26.6-43.4$ \\
4 & 13 & 0 & $18.9 \pm 0.6$ & $16.3-24.2$ \\
\hline
\end{tabular}

Total number of trees, mortality, mean DBH and DBH range in the four identified groups. These groups are composed of neighbour trees with similar diameter. 


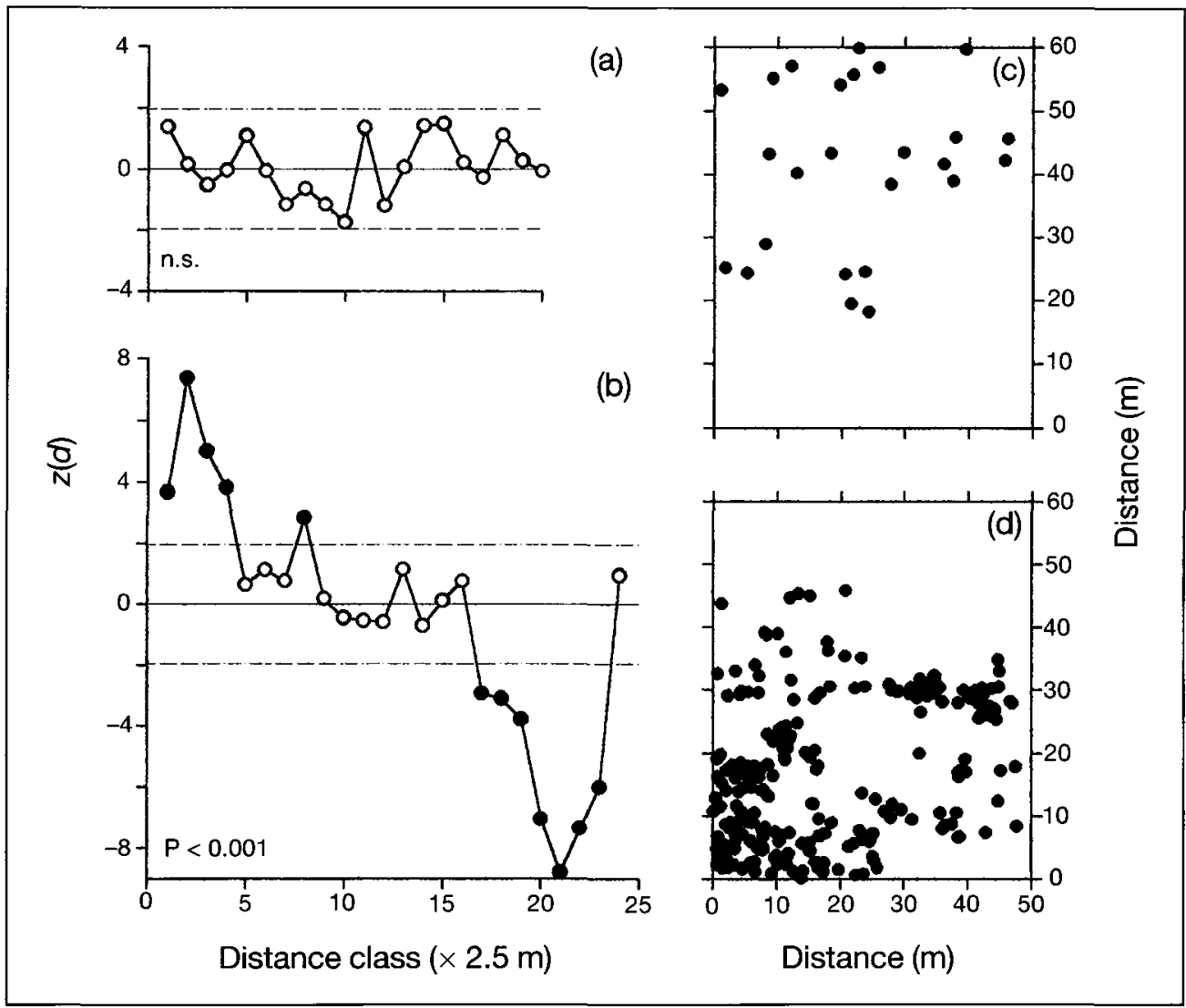

Fig. 3.-Spatial correlograms of Fagus sylvatica DBH in plots C2 (a) and C3 (b). Standard normal deviation z(d) of Moran's I coefficient in $2.5 \mathrm{~m}$ distance classes. Solid points: significant spatial autocorrelation at 0.05 level. The overall significance level of each correlogram is shown. n.s.: non significant. Spatial arrangement of the principal two groups of trees recognised in plot $\mathrm{C} 3$, group 1 (c) and group 2 (d), corresponding to the groups detailed in table 2.

the regeneration patterns of the studied tree species (VEBLEN, 1992). In plot C2, live + dead $F$. sylvatica trees with DBH $<30 \mathrm{~cm}$ were spatially independent from the live $F$. sylvatica with $\mathrm{DBH} \geq 30 \mathrm{~cm}$, except at distances of 4 and $5 \mathrm{~m}$, which showed a scarce intensity of repulsion (fig. 4a). Spatial interaction between the same groups of $F$. sylvatica trees in plot $\mathrm{C} 3$ was characterised by repulsion from 0 to $17 \mathrm{~m}$, and by independence from 18 to $25 \mathrm{~m}$ (fig. $4 \mathrm{~b}$ ).

Live Fagus sylvatica trees in plot C2 showed a clumped pattern at all analysed distances and were distributed more regularly than would be expected from random mortality at distances from 0 to $2 \mathrm{~m}$, but did not differ from this hypothesis at higher distances ( 3 to $25 \mathrm{~m}$; fig. 5a). Spatial interaction between the live and dead $F$. sylvatica trees in plot $\mathrm{C} 2$ was characterised by attraction at distances from 0 to $17 \mathrm{~m}$, according to the spatial independence hypothesis. Attraction from the null hypothesis of random mortality was also found at distances from 1 to $5 \mathrm{~m}$ and 8 to $14 \mathrm{~m}$ (fig. $5 \mathrm{~b}$ ). In plot $C 3$, live $F$. sylvatica were clumped at all analysed distances and were more uniformly spaced than would be expected given random mortality at distances of 3 to $24 \mathrm{~m}$ (fig. 5c). Living and dead $F$. sylvatica trees in plot $\mathrm{C} 3$ showed attraction from spatial independence hypothesis at all analysed 


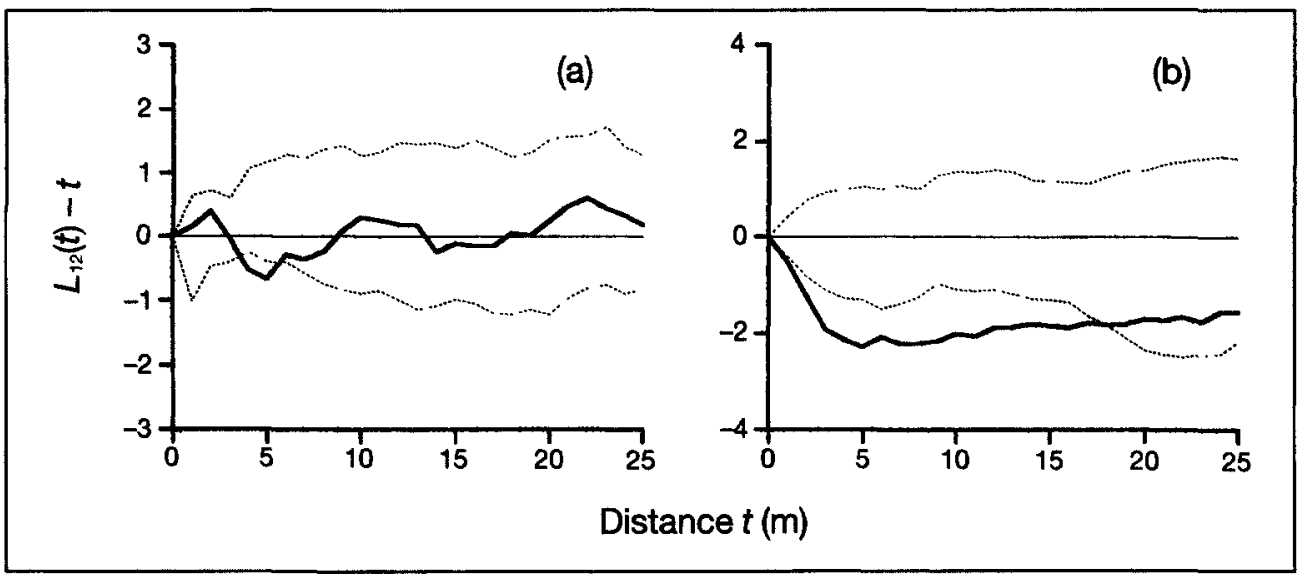

Fig. 4.- Spatial interaction between live + dead Fagus sylvatica trees with $\mathrm{DBH}<30 \mathrm{~cm}$ and live $F$. sylvatica trees with $\mathrm{DBH} \geq 30 \mathrm{~cm}$ in plots $\mathrm{C} 2$ (a) and C3 (b). Empirical function $L_{12}(t)-t$ (solid line) and $95 \%$ confidence intervals for spatial independence hypothesis (dotted lines) are plotted against distance $t$.

spatial scales, and also attraction from that expected given random mortality at distances of 3 to $25 \mathrm{~m}$ (fig. $5 \mathrm{~d}$ ).

Mean values of age, basal area increment during the last 5 years, and competition index within the most recent cohort of Fagus sylvatica, indicate an evident pattern of sizedependent variation in these three parameters, results being very similar in both the $\mathrm{C} 2$ and C3 plots. The hypothesis of identity in the distribution of these variables within different size classes was verified by means of the Kruskal-Wallis test, due to the heteroscedasticity of data. In plot $\mathrm{C} 2$ as well as in plot C3, age and basal area increment of $F$. sylvatica increased significantly with size, while competition index significantly decreased with size (table $3 ; H$ ranged between 16.48 and 71.14; d.f. $=3$ and $p<$ 0.001 in the six tests). Besides, mean age of

\section{TABLE 3}

AGE, GROWTH, AND COMPETITION, BY SIZE-CLASSES, FOR FAGUS SYLVATICA TREES OF THE MOST RECENT COHORT

\begin{tabular}{|c|c|c|c|c|}
\hline Plot & $\begin{array}{c}\text { DBH range } \\
(\mathrm{cm})\end{array}$ & Age (years) & $\begin{array}{c}\text { Basal area } \\
\text { increment }\left(\mathrm{cm}^{2}\right)\end{array}$ & $\begin{array}{c}\text { Total competition } \\
\text { index }\end{array}$ \\
\hline C2 & $5-9.9$ & $54.5 \pm 1.5(38)$ & $8.3 \pm 1.1(38)$ & $62.4 \pm 17.6(28)$ \\
& $10-14.9$ & $59.0 \pm 1.9(19)$ & $16.7 \pm 3.7(19)$ & $13.4 \pm 3.8(7)$ \\
& $15-19.9$ & $63.3 \pm 1.4(22)$ & $35.2 \pm 5.3(22)$ & $8.4 \pm 2.3(15)$ \\
& $20-45$ & $66.2 \pm 1.5(28)$ & $137.2 \pm 24.3(28)$ & $2.6 \pm 0.7(19)$ \\
\hline \multicolumn{2}{|c|}{ TOTAL } & $60.2 \pm 0.9(107)$ & $49.1 \pm 8.2(107)$ & $29.2 \pm 7.9(69)$ \\
\hline C3 & $5-9.9$ & $47.8 \pm 1.0(61)$ & $11.1 \pm 0.9(61)$ & $47.7 \pm 9.1(43)$ \\
& $10-14.9$ & $51.6 \pm 1.0(37)$ & $40.7 \pm 3.5(37)$ & $16.3 \pm 3.7(19)$ \\
& $15-19.9$ & $54.5 \pm 2.2(14)$ & $82.8 \pm 8.5(14)$ & $4.0 \pm 0.9(2)$ \\
& $20-45$ & $55.9 \pm 3.1(4)$ & $123.6 \pm 27.5(4)$ & $2.4 \pm 0.2(3)$ \\
\hline \multicolumn{2}{|c|}{ ToTAL } & $50.1 \pm 0.7(116)$ & $33.0 \pm 3.3(116)$ & $35.5 \pm 6.3(67)$ \\
\hline
\end{tabular}

Mean value \pm 1 standard error and the sample size (in brackets) are shown. Tree growth is expressed as basal area increment in the last 5 years. Competition index was calculated considering as competitors all live trees from all the species, within a neighbourhood radius of $5 \mathrm{~m}$. 


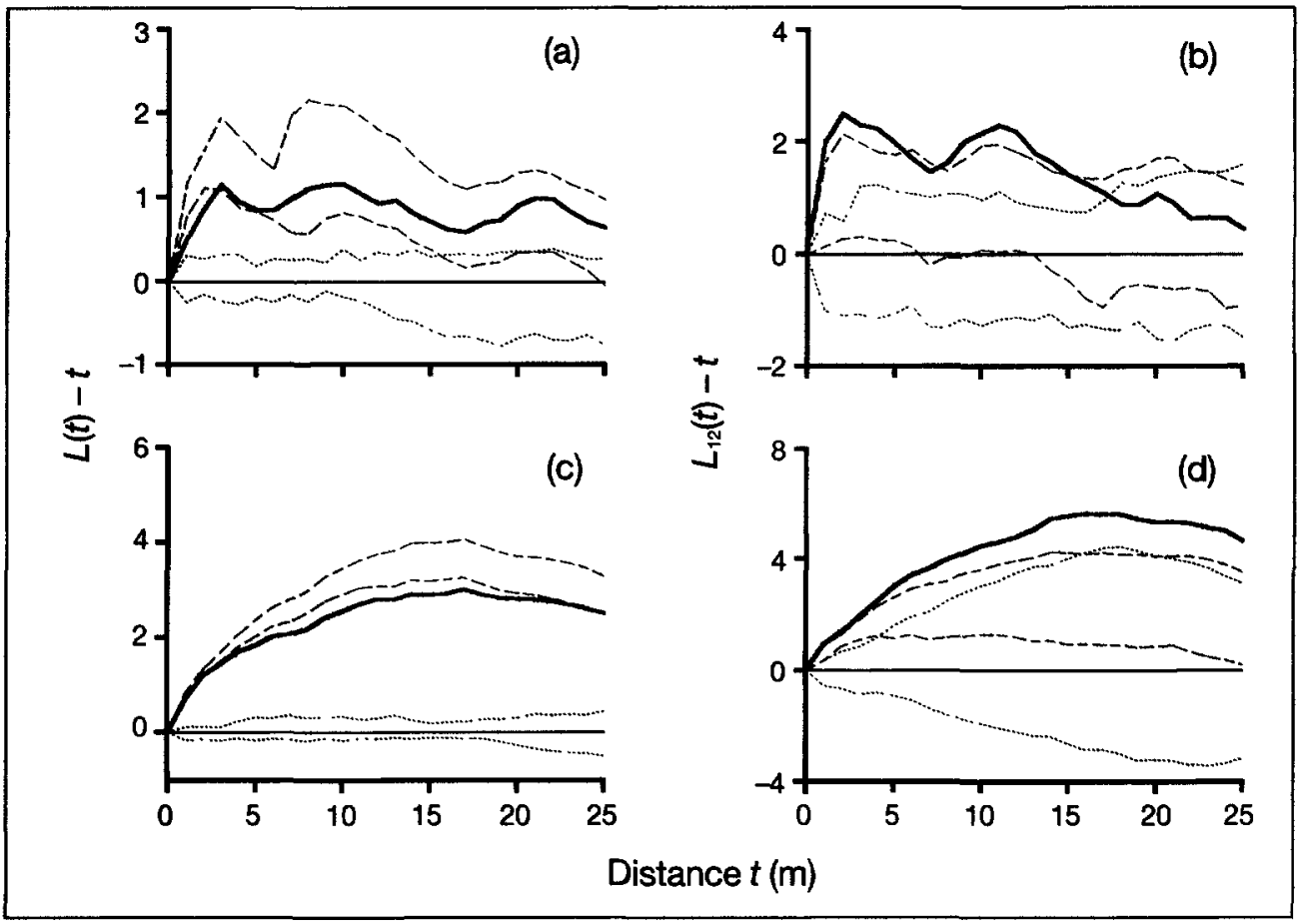

Fig. 5.-Spatial analysis of Fagus sylvatica mortality. Univariate analyses for live trees in plots C2 (a) and C3 (c). Bivariate analyses of spatial interaction between live and dead trees in plots C2 (b) and C3 (d). Dotted lines: $95 \%$ confidence intervals for spatial randomness (univariate) or independence (bivariate) hypotheses. Dashed lines: 95\% confidence intervals for random mortality hypothesis.

total $F$. sylvatica trees belonging to the recent cohort was significantly greater in plot $\mathrm{C} 2$ than in plot $\mathrm{C} 3$ (60.2 vs. 50.1 years; $t$ for unpaired data $=8.54$; d.f. $=221 ; p<0.001$ ) and mean competition index is significantly greater in plot $\mathrm{C} 3$ that in plot $\mathrm{C} 2$ (35.5 vs. $29.2 ; t=3.47$; d.f. $=134 ; p=0.001$ ). However, mean basal area increment during the last 5 years did not differ significantly between $F$. sylvatica trees of the recent cohort either in plots $\mathrm{C} 2$ or $\mathrm{C} 3(t=0.18$; d.f. $=221$; $p=0.855$ ). In plot $\mathrm{C} 2$, basal area increment of $F$. sylvatica trees belonging to the recent cohort was related to DBH in a direct way, and inversely related to age (least-squares regression: $\mathrm{BAl} 5=7.70 \mathrm{DBH}-1.62 \mathrm{Age}+$ $27.13 ; r^{2}=0.67 ;$ d.f. $=66 ; p<0.001$ ), while in plot C3 it was only related to DBH (leastsquares regression: $\mathrm{BAI} 5=6.79 \mathrm{DBH}$ $-36.31 ; r^{2}=0.76$; d.f. $=65 ; p<0.001$ ).

In both $\mathrm{C} 2$ and $\mathrm{C} 3$ plots, mean intraspecific competition index among Fagus sylvatica trees was significantly greater than mean interspecific competition index (plot $\mathrm{C} 2$ : MClintra $=18.8 \pm 4.1:$ MClinter $=10.4 \pm 6.4$; $t$ for paired data $=9.94 ;$ d.f. $=67 ; p<0.001$ and plot C3: MClintra $=22.6 \pm 4.2 ;$ MClinter $=12.8 \pm 4.1 ; t=5.52$; d.f. $=65 ; p<0.001$ ). Finally, partial correlations of competition indices with basal area increment during the last 5 years, were calculated for all $F$. sylvatica trees belonging to the most recent cohort in the plots $\mathrm{C} 2$ and $\mathrm{C} 3$ individually, as well as in the sum of both populations as a whole. In all cases, basal area increment showed a significant negative correlation with intraspecific competition, i.e. trees that suffered an intense interaction with conspecifics had slower growth rates (table 4). By contrast, interspecific competition and basal area increment were not significantly related, i.e. radial growth rates 
TABLE 4

PARTIAL CORRELATIONS BETWEEN BASAL AREA INCREMENT AND INTRA- AND INTERSPECIFIC COMPETITION INDEX

\begin{tabular}{|l|c|c|c|c|c|}
\hline Plot & $n$ & $\begin{array}{c}\text { Intraspecific } \\
\text { competition } \\
\text { index }\end{array}$ & $p$ & $\begin{array}{c}\text { Interspecific } \\
\text { competition } \\
\text { index }\end{array}$ & $p$ \\
\hline C2 & 69 & -0.27 & 0.022 & -0.06 & 0.623 \\
C3 & 67 & -0.25 & 0.040 & 0.09 & 0.450 \\
\hline TOTAL & 136 & -0.28 & 0.001 & -0.01 & 0.898 \\
\hline
\end{tabular}

Partial correlation coefficients were calculated taking as focal individuals the trees of the most recent cohort, from natural logarithms of basal area increment during the last 5 years and natural logarithms of competition indices.

of $F$. sylvatica trees were independent of interaction intensity with trees of other species (table 4).

\section{Discussion}

The age structure of Fagus sylvatica in plot $\mathrm{C} 2$ indicates that this population is predominantly composed of trees younger than 100 years old, having found only 4 trees older than 180 years old. Air photos taken in 1953 clearly show that plot C2 is located in a zone with parkland structure, with large scattered trees and much open space, a structure probably derived from its utilisation as pasture for cattle. The compound shape of $F$. sylvatica diameter distribution in plot C3 is characteristic of the shade-tolerant species which dominates the overstory of old-growth stands (LORIMER \& KRUG, 1983). This happens in plot $\mathrm{C} 3$ as in other mature forests mainly constituted by Fagus (KooP \& HILGEN, 1987; OHKUBO \& al., 1988) or shadetolerant Nothofagus species (VEBLEN \& al., 1980; Stewart \& Rose. 1990). The age structure in plot C3 shows abundant mature $F$. sylvatica trees older than 200 years as well as abundant regeneration during the last 80 years. Air photos also show that forest density in plot $\mathrm{C} 3$ has been high over the last five decades because this plot is located in a zone with high-forest structure. Establishment of the most recent cohort of $F$. sylvatica began over 20 years earlier in plot $\mathrm{C} 2$ than in plot $\mathrm{C} 3$, with an average age for this cohort of 60 years in plot $\mathrm{C} 2$ and 50 years in plot $\mathrm{C} 3$, both significantly different (see results). However, differences in specific dates of tree establishment did not rend any apparent relationship to contrast between the dynamics of both studied populations.

Lack of spatial structure of Fagus sylvatica population in plot $\mathrm{C} 2$ is shown by both the spatial pattern analyses for different size classes (fig. 2a) and the spatial correlogram of DBH (fig. 3a). Trees with less than $30 \mathrm{~cm}$ in DBH are distributed with small aggregation intensity or in a random way, while the largest size class presents a random or regular pattern of small intensity, depending on the spatial scale chosen. Furthermore, $F$. sylvatica population of $\mathrm{C} 2$ presents a mortality pattern which is also characteristic of density dependence: dead trees are only present in the smaller size classes, live trees show a uniform pattern at very short distance, and live and dead trees show spatial attraction at short and mean distances. Thus, $F$. sylvatica mortality in plot $\mathrm{C} 2$ occurs not at random, and is a consequence of intraspecific competition between trees located in close proximity (ANTONOVICS \& LEVIN, 1980; KENKEL, 1988), specifically at distances from 0 to $2 \mathrm{~m}$.

The greatest part of Fagus sylvatica trees in plot $\mathrm{C} 2$ belong to the cohort established without space limitation. Therefore development of this cohort was similar to that expected from classic models, based on the study of monocultures on homogeneous substrate (ANTONOVICS \& LEVIN, 1980; WEINER, 1984; KENKEL, 1988). In consonance with a widely accepted and experimentally ratified model, interaction between neighbour trees belonging to the same cohort was not symmetrical. According to the model, competition would increase growth rate variability and, by so much, magnify size differences between close neighbours from those expected with scarce (or without any) competition (WEINER, 1990). In agreement with these hypotheses, the sizes of neighbour $F$. sylvatica in plot $\mathrm{C} 2$ were independent, and basal area increments were directly 
proportional to size, therefore the asymmetrical intraspecific competition indeed contributed to increase differences in size of neighbouring trees along the development of the most recent cohort. Size differences between adjacent trees permitted the large sized individuals to reach a dominant position in the canopy, increasing their capacity to continue growing and confining underlying individuals to grow in an increasingly reduced space (OLIVER \& LARSON, 1996). Therefore, small-sized trees in the plot $\mathrm{C} 2$ presented little radial growth since they were subjected important competition intensity on a small spatial scale, and died when competition with larger neighbours was intense enough.

The size-class 4 of Fagus sylvatica in plot C2 included 9 trees younger than 80 years, 5 trees of 80 to 120 years in age, and 4 trees older than 180 years. Thus, the bivariate pattern obtained in figure $4 \mathrm{a}$ indicates only independence between different size-classes in this population, but it is not related to the spatial interaction between different cohorts and therefore indicates nothing on regeneration pattern of $F$. sylvatica in plot $\mathrm{C} 2$. The not very intense clumped pattern of the small-sized trees in plot $\mathrm{C} 2$ is not a consequence of regeneration limited to concrete zones, but of the growth rate diversification between neighbouring trees as a result of asymmetrical competition. The prevalent uniform pattern in the greatest sizeclass could be a consequence of intraspecific competition on radial growth and mortality, since the stochastic processes of tree losses by wind or decline of dominant trees has not had any incidence yet in plot $\mathrm{C} 2$. A similar spatial structure has been described in plots with a scarce disturbance regime (MOEUR, 1993) in which the competition processes that lead toward an increasingly regular distribution while increase the size of trees are expressed without participation of exogenous factors that could modify the final pattern.

In plot $\mathrm{C} 3$ the smaller size classes of $\mathrm{Fa}$ gus sylvatica were clumped, while bigger trees showed a random pattern, which is in agreement with results obtained in other old-growth forests (VEBLEN \& al., 1980;
NAKASHIZUKA \& NUMATA, 1982a, 1982b; OHKUBO \& al.. 1988; DUNCAN, 1993; TAYLOR \& al., 1996). Although spatial pattern analyses in some of the above mentioned publications were made by means of different methods than Ripley's $K$ function (Morisita's index and Iwao's method), all their results suggest that the main spatial pattern of large trees in old-growth forests is random or near random. The existence of a random pattern is a normal result of the transformation of an initial clumped pattern caused by self-thinning (LEPS \& KINDLMANN, 1987). Therefore, it is incorrect to deduce the independence of individuals within a forest stand from the observed random pattern since competition between neighbouring trees does not necessarily originate regular spatial patterns. Furthermore, it is very probable that past competition between trees could be not reflected in the current spatial distribution of live trees (SZWAGRZYK, 1992). The influence of exogenous factors along the history of plot C3, such as disturbances that might have eliminated dominant trees of the main canopy, could have conditioned the final pattern, making it depart from the one expected, if only the competition had exerted its effect. Thus, the effects of self-thinning as well as some exogenous factors acting on tree growth and mortality are sufficient to explain the random pattern of large $F$. sylvatica trees in plot $\mathrm{C} 3$.

The correlogram of Fagus sylvatica size in plot C3 shows positive autocorrelation at small distance classes, no autocorrelation at intermediate distance classes and negative autocorrelation at large distance classes (fig. 3b), which indicates a spatial gradient in tree diameter distribution (LEGENDRE \& FORTIN, 1989). This result agrees with the spatial arrangement of the two principal groups of trees identified, with large diameter dominance in a half of the plot while small diameter trees dominate the other half. Similar results have been obtained in other spatial autocorrelation analyses of size (SAKAI \& ODEN, 1983) and age (DUNCAN \& STEWART, 1991) in natural tree populations. The gradient structure of $\mathrm{DBH}$ seems to 
be related to the regeneration pattern of $F$. sylvatica in plot $\mathrm{C} 3$, which occurred segregated from the mature trees of their own species. This is quite a logical conclusion, because size-class 4 of $F$. sylvatica in plot $\mathrm{C} 3$ was composed of a 64 year old tree, a 175 year tree, and 33 mature trees of more than 200 years. For this reason, the bivariate pattern of figure $4 \mathrm{~b}$ is an adequate indicator of the large spatial repulsion with which the regeneration occurred in relation to the mature trees.

Fagus species are always more shadetolerant than the other coexisting deciduous trees throughout the entire north hemisphere (PETERS, 1992), $F$. sylvatica being the most shade-tolerant broadleaf tree species in Europe (Peterken, 1996). However, the regeneration of different Fagus species is very difficult under a canopy of their own species, mainly due to the great capacity of light assimilation that adult Fagus trees possess. Therefore, Fagus regeneration takes place mostly in canopy gaps and less dense canopy zones, in which young trees reach often large densities (NAKASHIZUKA \& NuMATA, 1982a, 1982b; KOOP \& HilgeN, 1987; ОнкUво \& al., 1988). Thus, the highly organised spatial structure of $F$. sylvatica population in plot $\mathrm{C} 3$ would be mainly a consequence of the occurrence of regeneration as a density-dependent process along the last 80 years. Tree regeneration took place segregated from the previous cohort, the size of neighbour trees being similar and, since basal area increment depends to a large extent on tree size, this similarity would have perpetuated over time.

In plot C3 dead trees were found in the smallest size class of the most recent cohort as well as in the smallest size classes of the most ancient cohort (fig. 1c). That is to say, two types of Fagus sylvatica mortality levels would coexist in plot C3: (1) tree mortality within the cohort established at 30 to 80 years ago, and (2) mortality of the trees of 170 to 270 years old. Distribution patterns of $F$. sylvatica trees in plot $\mathrm{C} 3$ differed significantly from that expected given random mortality. Both a uniform pattern for live trees and spatial attraction between live and dead trees, from that which would be expected from random mortality, were observed in nearly all the analysed distances. Except for very short distances $(<3 \mathrm{~m})$ or very long distances $(>24 \mathrm{~m}$ ), intraspecific competition produced mortality of $F$. sylvatica trees in plot C3 (DUNCAN, 1991). Current models predict that if intraspecific competition causes tree mortality live trees will be more uniformly spaced than would be expected from random mortality at small spatial scale (KENKEL, 1988). This was observed in plot $\mathrm{C} 2$ and in other natural tree populations (DUNCAN, 1991). Lack of evidence of competition at short distance in the recent cohort of $F$. sylvatica in plot $\mathrm{C} 3$ can be well explained by the great size similarity of neighbouring trees. The existence of tree groups with very similar size was reflected in the highly significant positive autocorrelation at distances up to $10 \mathrm{~m}$ (fig. 3b). The great majority of dead trees in the $F$. sylvatica population of plot $\mathrm{C} 3$ were found within group 2 and the greatest difference in DBH between the individuals of this group was around $15 \mathrm{~cm}$ (table 2). Therefore, in this case there was not an intense intraspecific competition at small spatial scale exerted by the greater sized trees. $F$. sylvatica mortality in plot $\mathrm{C} 3$ was rather a consequence of the competition exerted by a great number of individuals of a very similar size, and located in a very wide distance range.

In summary, within the two Fagus sylvatica populations under study, age and size were directly related, and both radial growth and mortality depends on intraspecific competition. However, the notable differences concerning spatial organisation and mortality patterns observed between populations could be a consequence of regeneration development under very different conditions. Recent cohort establishment in one plot occurred without space limitations, due to the scarce presence of mature trees. Size hierarchy in this population, mainly composed of even-aged individuals, could have been originated by the asymmetric intraspecific competition between neighbouring trees. The main 
consequence of this is the absence of a recognisable structure in the spatial arrangement of tree size, with great differences in the sizes of neighbouring trees. Thus tree mortality in this population was a result of the asymmetrical competition exerted by large sized trees on adjacent suppressed individuals. On the other hand, in the population constituted by two welldifferentiated principal cohorts, establishment of new individuals was limited by the existence of an old-aged cohort that monopolised an extensive area of the plot surface. Thus, tree regeneration was densitydependent, resulting in a size hierarchy mainly conditioned by differences in age, as well as in a clear spatial structure in those groups composed of even-sized trees. Tree mortality pattern, in this case, resulted from the competition exerted by a great number of individuals very similar in size over a wide distance range.

\section{ACKNOWLEDGEMENTS}

The Junta Vecinal de Caviedes gave the needed permission for the accomplishment of fieldwork. We are indebted to Richard Duncan and Melinda Moeur for kindly offering us their own original software for quantitative spatial analysis. We thank Luis Cabo and Kenneth McKenney for English language assistance.

\section{REFERENCES}

Allue, J.L. (1990). Atlas fitoclimático de España. MAPA, Instituto Nacional de Investigaciones Agrarias, Madrid.

ANTONOVICS, J. \& D.A. LEVIN (1980). The ecological and genetic consequences of density-dependent regulation in plants. Annual Rev. Ecol. Syst. 11: 411-452.

DUNCAN, R.P. (1991). Competition and the coexistence of species in a mixed podocarp stand. J. Ecol. 79: 1073-1084.

Duncan, R.P. (1993). Flood disturbance and the coexistence of species in a lowland podocarp forest, south Westland, New Zealand. J. Ecol. 81: 403-416.

DunCaN, R.P. \& G.H. StEwart (1991). The temporal and spatial analysis of tree age distributions. Can. $J$. For. Res. 21: 1703-1710.

Guitian, F., T. Carballas, F. Diaz-Fierros \& M. Plata (1985). Suelos naturales de Cantabria. CSIC,
Instituto de Investigaciones Agrobiológicas de Galicia, Santiago de Compostela.

HaAse, P. (1995). Spatial pattern analysis in ecology based on Ripley's K-function: introduction and methods of edge correction. J. Veg. Sci. 6: 575-582.

IGME (1976). Comillas. Mapa Geológico de España, E. 1:50.000. Ministerio de Industria, Servicio de Publicaciones, Madrid.

KENKEL, N.C. (1988). Pattern of self-thinning in jack pine: testing the random mortality hypothesis. Ecology 69: 1017-1024.

KOOP, H. \& P. HILGEN (1987). Forest dynamics and regeneration mosaic shifts in unexploited beech (Fagus sylvatica) stands at Fontainebleau (France). For. Ecol. Manag. 20: 135-150.

LEGENDRE, P. \& M.J. ForTIN (1989). Spatial pattern and ecological analysis. Vegetatio 80 : 107-138.

LEPS, J. \& P. KINDLMANN (1987). Models of the development of spatial pattern of an even-aged plant population over time. Ecol. Model. 39: 45-57.

Lieberman, M.. D. Lieberman \& R. Peralta (1989). Forests are not just swiss cheese: canopy stereogeometry of non-gaps in tropical forests. Ecology 70: 550-552.

LONG, J.N. \& F.W. SMITH (1984). Relation between size and density in developing stands: a description and possible mechanisms. For. Ecol. Manag. 7: 191-206.

LORIMER, C.G. (1983). Tests of age-independent competition indices for individual trees in natural hardwood stands. For. Ecol. Manag. 6: 343-360.

Lorimer, C.G. \& A.G. KRUG (1983), Diameter distributions in even-aged stands of shade-tolerant and midtolerant tree species. Am. Midl. Nat. 109: 331-345.

MOEUR, M. (1993). Characterizing spatial patterns of trees using stem-mapped data. For. Sci. 39: 756-775.

NAKAShIZUKA, T. \& M. Numata (1982a). Regeneration process of climax beech forests I. Structure of a beech forest with the undergrowth of Sasa. Jap. J. Ecol. 32: 57-67.

NAKASHIZUKA. T. \& M. Numata (1982b). Regeneration process of climax beech forests II. Structure of a forest under the influences of grazing. Jap. J. Ecol. 32: 473482.

OHKubo, T., M. KaJI \& T. Hamaya (1988). Structure of primary Japanese beech (Fagus japonica Maxim.) forests in the Chichibu Mountains, central Japan, with special reference to regeneration processes. Ecol. Res. 3: 101-116.

Oliver, C.D. \& B.C. LARson (1996). Forest Stand Dynamics. Update Edition. Wiley and Sons, New York.

PETERKEN, G.F. (1996). Natural Woodland. Ecology and Conservation in Northern Temperate Regions. Cambridge University Press, Cambridge.

Peters, R. (1992). Ecology of Beech Forests in the Northern Hemisphere. Ph.D. Thesis, Wageningen Agricultural University, The Netherlands.

RozAS, V. (1999). Estructura, dinámica y tendencias sucesionales en un bosque de roble y haya de la Cornisa Cantábrica. Ph.D. Thesis (unpublished manuscript), Universidad de Oviedo, Spain. 
SAKAI, A.K. \& N.L. ODEN (1983). Spatial pattern of sex expression in silver maple (Acer saccharinum L.): Morisita's index and spatial autocorrelation. Am. Nat. 122: 489-508.

STEWART, G.H. \& A.B. Rose (1990). The significance of life history strategies in the developmental history of mixed beech (Nothofagus) forests, New Zealand. Vegetatio 87: 101-114.

SZWAGRZYK, J. (1992). Small-scale spatial patterns of trees in a mixed Pinus sylvestris-Fagus sylvatica forest. For. Ecol. Manag. 51: 301-315.

TAYLOR, A.H., Q. ZISHENG \& L. JIE (1996). Structure and dynamics of subalpine forests in the Wang Lang Natural Reserve, Sichuan, China. Vegetatio 124: 25-38.

Upton, G.J. \& B. Fingleton (1985). Spatial Data Analysis by Example. Vol. 1. Point Pattern and Quantitative Data. Wiley and Sons, Chichester.
VeBLEN. T.T. (1992). Regeneration dynamics. In: D.C. Glenn-Lewin, R.K. Peet \& T.T. Veblen (eds.), Plant Succession: Theory and Prediction: 152-187. Chapman and Hall, London.

Veblen, T.T., F.M. Schlegel \& B. Escobar (1980). Structure and dynamics of old-growth Nothofagus forests in the Valdivian Andes, Chile. J. Ecol. 68: 1-31.

WARD, J.S., G.R. PARKER \& F.J. Ferrandino (1996). Long-term spatial dynamics in an old-growth deciduous forest. For. Ecol. Manag. 83: 189-202.

WEINER, J. (1984). Neighbourhood interference amongst Pinus rigida individuals. J. Ecol. 72: 183-195.

WEINER, J. (1990). Asymmetric competition in plant populations. Trends Ecol. Evol. 5: 360-364.

Editado por Carlos Aedo Aceptado para publicación: 14-XII-1999 